\title{
Prospects of underground parking during the reconstruction in the center of St. Petersburg
}

\author{
Natalya Braila ${ }^{1,}$, , Maria Znobishcheva ${ }^{1}$, Nikolai Panchenko ${ }^{1}$ and Mikhail Kostyshak ${ }^{2}$ \\ ${ }^{1}$ Peter the Great Saint-Petersburg Polytechnic University, 195251, 29 Polytechnicheskaya st, Saint- \\ Petersburg, Russia \\ ${ }^{2}$ Moscow State University of Civil Engineering, 26, Yaroslavskoeshosse, 129337, Moscow, Russia
}

\begin{abstract}
The aim of the work is to assess the possibility of underground parking during the reconstruction of objects located in the historical part of St. Petersburg. Using theoretical research methods, an analysis of typical problems during reconstruction with the development of the underground space is carried out, widely used work production technologies are identified, and the experience gained from such construction in St. Petersburg is evaluated. The result of the study was the conclusion about the possibility of constructing in-depth and semi-in-depth parking lots, as well as the reconstruction of existing buildings with underground parking in the central historical part of the city. At the same time, a high probability of significant restrictions or even a ban on reconstruction was noted. In addition, under the constrained conditions of historical development, highquality, thorough and systematic implementation and monitoring of repair and construction work by professional geotechnicians and builders is required.
\end{abstract}

\section{Introduction}

According to the traffic police, the total number of registered vehicles in St. Petersburg reached 2.4 million in 2017, whilst there are only 500000 parking spaces in all existing parking lots, garages, built-in and attached parking lots.

According to the forecast, the level of motorization for the population of St. Petersburg will increase from 242 cars per 1000 people in 2006 to 450 cars per 1000 people by 2025 [1].

It is especially important to provide places for temporary and permanent storage of passenger cars in the central part of the city, where transport is increasingly taking up lawns, sidewalks, and recreation areas instead of designated places for it. This is due to the lack of parking spaces, including residential areas, and the non-compliance of the regulatory and technical base with modern requirements of urban planning [2-6].

Currently, parking on many streets in the city center is to be paid, and initiatives are being considered to expand the paid parking zone, as well as the possibility of paid entry. These measures will reduce the number of cars entering the center and improve the

\footnotetext{
* Corresponding author: nashi-n-v@mail.ru
} 
situation for public transport. However, they will not solve the problem of parking even for residents of the historical part of St. Petersburg.

Thus, it is relevant to assess the possibility of building ground parking lots, or their organization in the underground space, including in buildings after reconstruction.

Among other advantages, this solution will allow shifting cars underground and make courtyards pedestrian. Recreation areas and playgrounds will no longer intersect with traffic flows. There will also be more space available for landscaping and recreation areas.

Moreover, the use of underground parking can improve the environmental situation, which is reflected in the study [7].

\section{Methods}

\subsection{Problems of underground space development in Saint Petersburg}

There are a number of reasons that hinder the implementation of underground parking projects in the center of St. Petersburg:

1. High cost of land plots. The investment attractiveness of such projects is called into question, because the cost of parking space may be unattainable for most owners of vehicles.

2. Complex engineering and geological condition. The historical center of St. Petersburg is built on weak water-saturated soils. Furthermore, the foundations of many buildings of the XVIII and early XX centuries are composed of masonry of rubble, granite or limestones, the depth of the foundation is from 1.5 to 3 or 4 meters. Objects have cracks and violations in the work of structures.

In addition, the central part of the city is protected by UNESCO, which limits the choice in design solutions not only for the reconstruction of existing, but also for the construction of new facilities.

Thus, taking into account the density of historical buildings, high care is required in choosing geotechnical technologies and solutions for reconstruction.

3. Lack of a comprehensive strategy for underground space development, which should not only be a general plan for urban underground space development, but also a vision of the reasons why this should be done $[8,9]$.

\subsection{Experience in building underground structures in Saint Petersburg}

Solving a wide range of architectural, social, economic, and environmental problems is impossible without systematic and integrated use of underground space. The analysis of foreign experience of underground space development in big cities is successful [8-14].

The development of underground space in St. Petersburg began with mistakes. During the construction of the hotel on Nevsky Avenue 57, the transport and commercial center of high-speed highways near the Moscow railway station and the residential building No. 6 on Michurinskaya street, neighboring historical buildings, which are significant architectural monuments, were completely destroyed and dismantled. The reason for the accidents was the use of foreign geotechnologies without their adaptation to the difficult ground conditions of the region. But in the period from 2006-2009, complex projects were successfully implemented, which provided for the construction of deep underground structures in dense urban development.

1. Work on the reconstruction of the Konstantinovsky Palace with a significant complex of geotechnical works, including the deepening of existing basements under the terrace. 
Prior to the work, the building was a structure with significant damage, sometimes of an emergency nature.

2. According to the Institute of architectural and construction design, geotechnics and reconstruction "Georekonstruktsiya" (georeconstruction), when constructing an underground space with a depth of 6.5 meters under the Kamennoostrovsky Theater, the "top-down" technology was implemented for the first time in St. Petersburg in a modified form: the underground space was constructed down, and the restoration of a historical building was carried out up simultaneously. Herewith, at the international restoration exhibition "Denkmal" in Leipzig, the object was named the standard of modern restoration.

3. Arrangement of the underground volume of the Mariinsky Theatre second stage under the entire building. The concept of development of the ditch provided for the system of external and internal walls of the fence. The entire range of possible geotechnologies was exhausted by vibration loading of the sheet pile with the subsequent arrangement of multilevel spacer structures. The impact of the sheet pile vibration loading technology on neighboring buildings did not exceed acceptable values [15].

4. Construction of an underground space up to 15 meters deep in the Stockmann shopping center. The task of ensuring the safety of the existing building, which is closely adjacent to the ditch, arranged using the "top-down" technology, was solved at this site [16].

5. Reconstruction of a number of buildings on Pochtamtskaya street for office and hotel complexes. According to the Institute of architectural and construction design, geotechnics and reconstruction "Georekonstruktsiya" (georeconstruction), the sediment of neighboring buildings for the entire period of construction did not exceed $1 \mathrm{~cm}$, which is the best proof of the effectiveness of design solutions. The object is a refutation of the popular opinion that underground construction in St. Petersburg is impossible without damage and mandatory reinforcement of neighboring buildings. In this case, a method of fairly complex reconstruction was successfully implemented using the capabilities of inkjet technology.

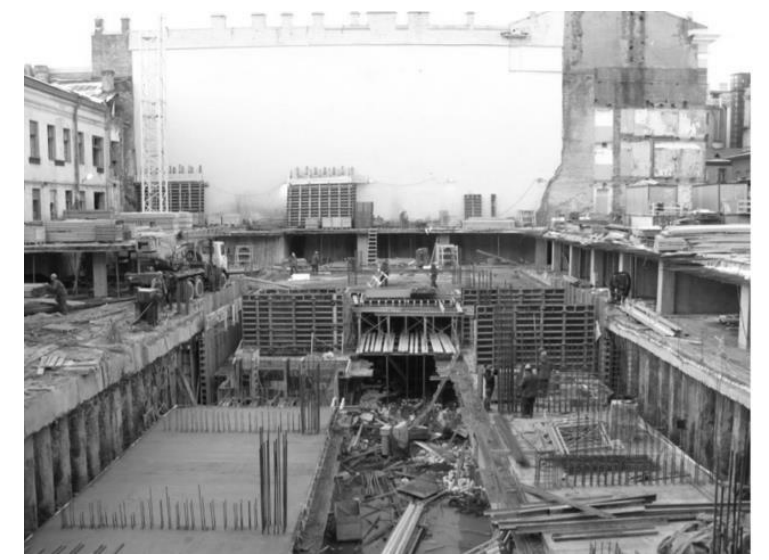

Fig. 1. A ditch for the construction of underground parking safe during the reconstruction of buildings on Pochtamtskaya.

6. Luxury residential building on Zoological lane. Here, the slurry wall technology was first used in St. Petersburg in conditions of dense development. This opened up the possibility of developing underground space in St. Petersburg at the modern geotechnical level. The possibility of building ground parking lots in the central part of St. Petersburg has already been exhausted due to both the lack of free territory and its high cost for such projects. However, existing experience shows that the construction of underground parking is a real way to develop the urban environment. 


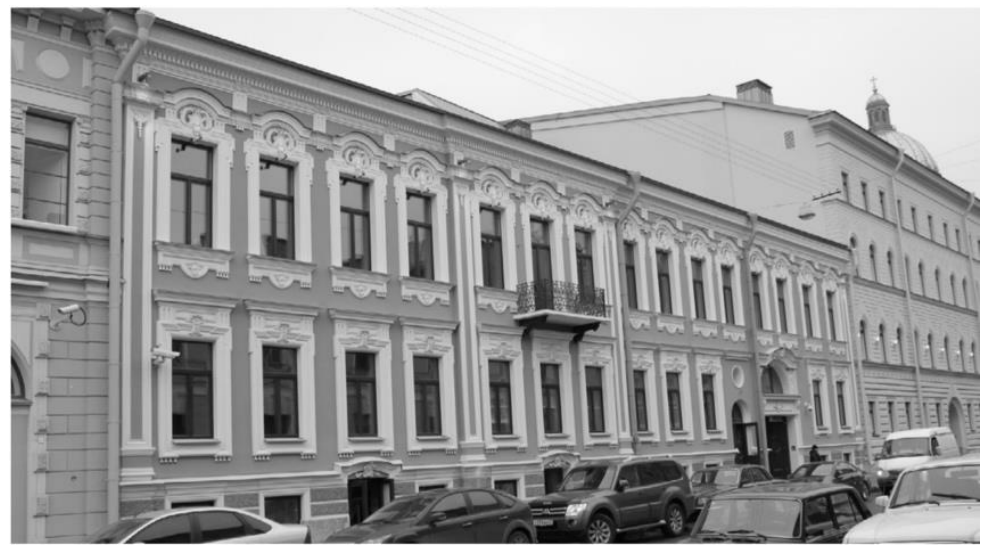

Fig 2. Restored facade of the building on Pochtamtskaya.

\subsection{Technologies used in the construction of underground structures in St. Petersburg}

Currently, when building underground structures in the center of St. Petersburg, the "topdown" technology with a ditch fence in the form of slurry wall is widely used. This is due to the fact that this method allows working almost simultaneously on the construction of the underground and ground parts of the building, which respectively speeds up the construction time. It is also important to note that this method allows minimizing the deformation of the enclosing structures and, accordingly, the precipitation of neighboring buildings.
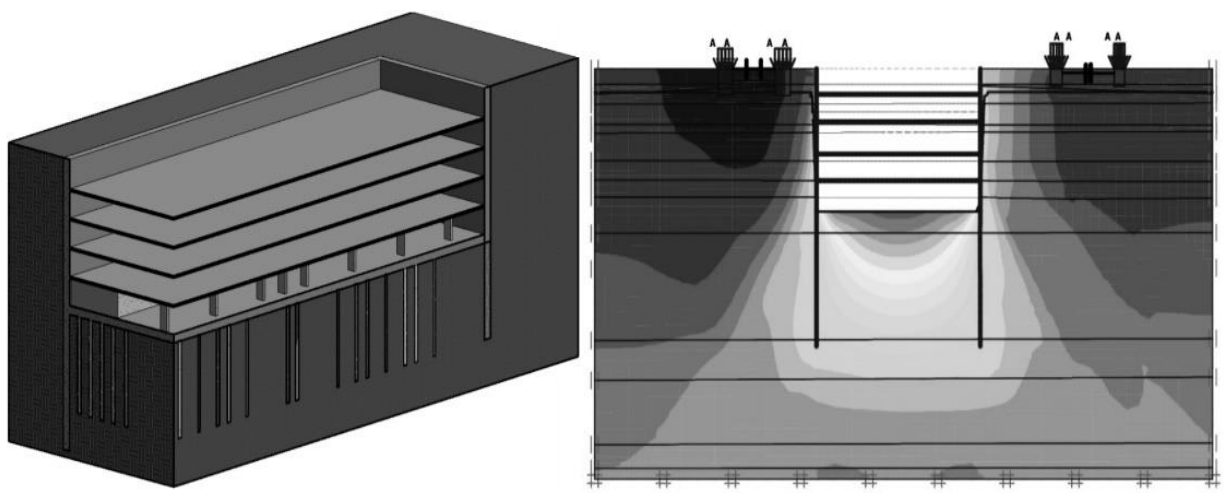

Fig. 3. Overall view of the calculation scheme for the "Top-Down" method and isofield of the total displacement built in PLAXIS.

The use of "top-down" technology requires participants in the construction process to strictly follow the sequence of work and comply with labor protection standards on the site, as a large number of complex engineering solutions are used.

A similar construction method is a "semi top-down". Its main difference from "topdown" is that most of the earthworks are performed in an open way, using excavators and a much smaller amount of work is carried out under the protection of overlaps. In addition, the construction of the above-ground part is performed only after the completion of work in the underground part of the building. 
Such modern technology as jet cementation of weak soils "jet grouting" allows developing design solutions that are safer for surrounding buildings and optimal in terms of costs. It was successfully used in the reconstruction of a number of buildings on Pochtamtskaya street in the historical center of St. Petersburg.

Thus, since 2006, construction technologies that minimize the impact of underground construction on the surrounding buildings have been used in a large number of projects. Moreover, due to the frequency of use of these technologies, they are unified with each project, additional regulatory documents and technological maps are developed, which reduces labor costs and increases their efficiency.

\section{Results}

Many of the buildings in the historical part of the city are architectural masterpieces that have no analogues in Europe or in the rest of the world. In 1990, the "Historical center of Saint Petersburg and its associated complexes of monuments" were included in the UNESCO world heritage list.

For cultural heritage sites protected by UNESCO, it is not possible to demolish and erect new residential buildings in their place that meet the modern requirements of comfortable housing. As a result, the only alternative remains the reconstruction of the existing historical building with adaptation to modern conditions of use [17].

One of the most popular actions to increase investment attractiveness, as well as to improve living conditions in historical houses in the center of St. Petersburg is the construction of an underground parking [17]. Of course, underground parking is not the best investment for investors in terms of profitability, the city administration is also unlikely to invest in such projects. The profitability of such a project is reduced even more significantly when installing underground parking during the reconstruction of an existing building in the center of St. Petersburg. Dense historical buildings, cramped conditions, the proximity of architectural monuments, the need to take into account the underground infrastructure of the city such as utilities, tunnels and metro lobbies, lead to an increase in the complexity and, consequently, the cost of the underground parking project.

Basing on the existing world experience, as well as the examples described in the article earlier, we can conclude that the construction of underground parking directly under the existing building is possible, but there may be significant restrictions or even a ban on reconstruction. For example, the object is protected by the KGIOP (Committee for state control, use and protection of historical and cultural monuments) and changing its technical and economic parameters is prohibited. An alternative solution is the possibility of underground parking, for instance, under the territory of the courtyard or on the site of old non-functioning wings. Examples of such development of underground space are the possible projects considered in [17] on Liteyny Avenue, 46, and 24 on Kirochnaya street in the courtyard of the famous Baka building.

For any underground construction in the historical part of St. Petersburg, due to special conditions, it is necessary to perform a number of measures that will ensure uninterrupted construction and exclude the possibility of any accidents and destructions. First of all, a preliminary calculation of the foundation sediment of nearby buildings is required, it can be done with the help of the PLAXIS software package, and further regular monitoring of the construction process is strictly required. This will allow timely adjusting the construction process, eliminating the occurrence of excessive non-uniform deformations. Also, for safety reasons, it is necessary to perform preventive strengthening of foundations, for example, using the "jet grouting" technology, and if necessary, strengthen other structures of buildings located within the radius of influence of underground construction. 


\section{Conclusion}

Thus, the construction of underground parking in the cramped conditions of the central historical part of St. Petersburg during the reconstruction of buildings is possible, but only with high-quality, thorough and systematic implementation and monitoring of works by professional geotechnicians and builders.

In the absence of free territory, the need to preserve the historical appearance of the central part of St. Petersburg, and the constant increase in the number of vehicles, mass construction of underground parking lots is a possible way to solve the problem under consideration. The implementation of the described plan is possible only with a comprehensive approach to the implementation of underground construction, which will include:

1. A full range of geotechnical investigations at all stages of construction and putting the object into operation;

2. Study of new construction technologies and building materials that will help optimize labor costs and the cost of work;

3. Development of a set of measures for the development of the underground space of St. Petersburg;

4. Making necessary amendments to current local legislation;

5. When building deepened or semi-deepened parking lots, it is recommended to use the "top-down" technology to reduce the impact on the surrounding development.

By now, there are regulatory documents in the field of underground construction in St. Petersburg designed to regulate the industry in question. Moreover, the introduced Western technologies of underground construction in the 90ies were rethought and adapted to local engineering and geological conditions. All this shows that the process of developing underground space is possible even in such difficult conditions. But the lack of a centralized concept and strategy, and the state's interest in this process, seriously slows down the development of underground space.

\section{References}

1. I. Duvanova, T. Bubnova, M. Romanovich, Procedia Engineering, 165, 1794-1800 (2016). DOI: https://doi.org/10.1016/j.proeng.2016.11.924

2. I. A. Duvanova, T. L. Simankina, Construction of Unique Buildings and Structures, 2(41), 108-117 (2016). DOI: 10.18720/CUBS.41.8

3. I. A. Duvanova, Construction of unique buildings and structures, 12(39), 43-56 (2015). DOI: $10.18720 /$ CUBS.39.3

4. A. Levashev, A. Mikhailov, I. Golovnykh, WIT Transactions on Ecreology and the Environment, 179, 1067-1076 (2013). DOI: 10.2495/SC130912

5. I. Molenda, G. Sieg, Economics of Transportation, 2(4), 131-139 (2013). DOI: 10.1016/j.ecotra.2014.02.002

6. J. Van Ommeren, J. De Groote, G. Mingardo, Regional Science and Urban Economics, 45, 33-44 (2014). DOI: https://doi.org/10.1016/j.regsciurbeco.2013.11.003

7. X. B. Yang, Z. L. Chen, H. Cai, Advanced Materials Research, 869-870,178-184 (2013). DOI: 10.4028/www.scientific.net/AMR.869-870.178

8. T. Simankina, N. Braila, S. Kanyukova, Original Research Article Procedia Engineering, $\quad \mathbf{1 6 5}, \quad 1757-1765 \quad$ (2016). https://doi.org/10.1016/j.proeng.2016.11.919 
9. A. Ushakova, Procedia Engineering, 165, 166-174 (2016). DOI: https://doi.org/10.1016/j.proeng.2016.11.748

10. O. Gamayunova, E. Gumerova, Procedia Engineering, 165, 1637-1642 (2016). DOI: https://doi.org/10.1016/j.proeng.2016.11.904

11. Official web site of the City of Sydney council. https://www.cityofsydney.nsw.gov.au/_ data/assets/pdf_file/0006/138804/WynyardPar kPoM1997.pdf

12. European Parliament resolution of 9 July 2008 on «Towards a new culture of urban mobility». http://www.europarl.europa.eu/sides/getDoc.do?type=TA\&reference=P6TA-2008-0356\&language $=$ EN\&ring=A6-2008-0252

13. A. Parriaux, P. Blunier, P. Maire, L. Tacher, 11th ACUUS International Conference, Underground Space: Expanding the Frontiers. 10-13 september 2007. Athens. Greece, 255-260. https://infoscience.epfl.ch/record/117440

14. E. F. J. de Mulder, H. R. G. K. Hack, C. C. D. F. van Ree, Sustainable Development and Management of the Shallow Subsurface, The Geological Society of London, (2012). DOI: https://doi.org/10.1144/MPSDM. ISBN electronic: 9781786203984

15 A. Benin, A. Konkov, V. Kavkazskiy, A. Novikov, N. Vatin, Procedia Engineering, 165, 1483-1489 (2016). DOI: https://doi.org/10.1016/j.proeng.2016.11.883

16. R. Mangushev, E. Rybnov, E. Lashkova, A. Osokin, Procedia Engineering, 165, 673681 (2016). DOI: https://doi.org/10.1016/j.proeng.2016.11.765

17. R. A. Mangushev, A. I. Osokin, P.G. Levinskaya, Housing construction, 4, 3-18, (2019). DOI: https://doi.org/10.31659/0044-4472-2019-4 